\title{
A dog's life
}

\section{Laika, the doomed stray, has achieved a kind of immortality.}

Space agencies rely on the public's interest in people and animals to sustain engagement with their programmes. Curiosity over the ill-fated Mars lander Beagle 2, for example, was undoubtedly boosted by its clever name. Striking images of astronauts and space animals have strongly contributed to the visual output from the agencies.

On 3 November 1957, the fortieth anniversary of the Russian Revolution, a dog was launched into Earth orbit in Sputnik 2. Russia had already launched numerous dogs into suborbital flight, with at least four fatalities. To place a dog in orbit was an achievement of an altogether different dimension, especially only a month after the launch of Sputnik 1.

The dog nicknamed Laika

을 ('Barker'), called 'Muttnik' in the American press, was selected from the cadre of trained dogs, all small $\underset{Z}{Z}$ female strays off the streets of Moscow. The BBC reported, "It is believed the Russians are planning to catapult the dog back to Earth, although there has been no official announcement confirming this". Predictably, animal-welfare groups were outraged. In Britain, the National Canine Defence League called for a minute's silence for each of the dog's days in space. The RSPCA advised protesters to assemble at the Russian embassy. Russian news releases, reluctantly acknowledging that Laika could not be returned to Earth, indicated that she remained healthy for some days. However, at the World Space Congress in Houston, Texas, in October 2002, Dimitri Malashenkov from the Institute for Biological Problems in Moscow admitted that Laika, stressed and overheated, probably survived for a maximum of seven hours.

The main photographs issued by the space agency show the attractive mongrel alert in her space harness and resting comfortably in her padded capsule. The former, which seemed to exude an air of bright courage, proved to be the more iconic. It was used on Mongolian and Romanian postage stamps, and to adorn souvenirs.

Heroically, Laika features prominently among the human space pioneers on the Monument to the Conquerors of Space in Moscow. Shortly after the launch of Sputnik 1, a competition was announced for the design of the monument. The winning

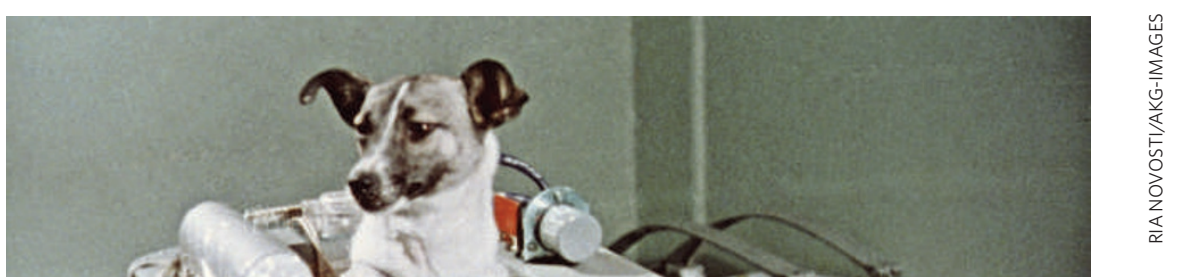

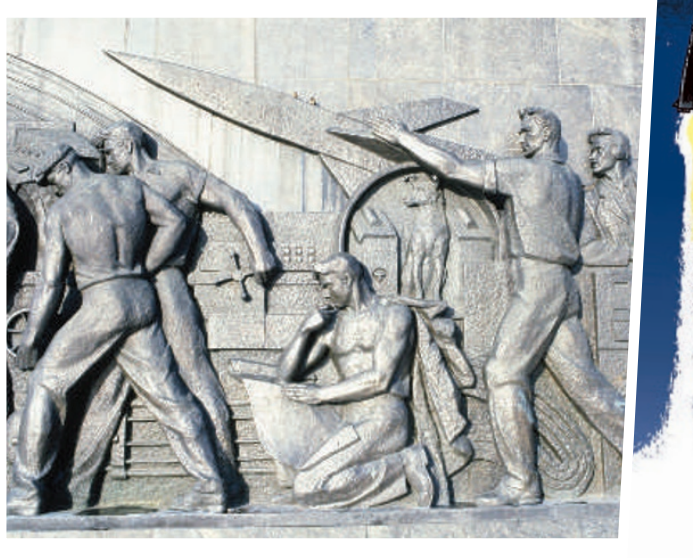

Laika lives on: in her padded capsule (top), on a monument to space heroes (left) and in an upcoming graphic novel.

entry was submitted by the sculptor A. P. Faidysh-Krandievsky and architects A. N. Kolchin and M. O. Barshch. The monument was inaugurated on 4 October 1964 , the seventh anniversary of the Sputnik 1 launch.

The monument assumes the form of a giant obelisk. At its summit is an ascending rocket, supported by a huge, tapering titanium slipstream. Around its base, which houses a museum, are sculpted reliefs of the space heroes. Laika's turned head and trace of the space harness are based on the classic photograph, but she is portrayed sitting within a simplified version of the capsule from the other image.

Laika has given her name to several pop groups, including the Finnish band Laika and the Cosmonauts and a successful UK-based ensemble founded in 1993 by Margaret Fiedler and Guy Fixsen. Even NASA named a soil target on Mars after her. Laika now even hosts a site on MySpace (http://profile. myspace.com/index.cfm?fuseaction=user. viewprofile\&friendID=109345281).

Laika, the doomed stray, has achieved a kind of immortality. Many humans over the ages have traded their lives for great causes, particularly religious martyrs, confident in their afterlife and that they will live on through the renown of their sacrifice. For a conscious being, such a choice is an option.

We may be comforted by the 'portraits' of Laika, and perhaps moved by their pathos, just as we are when looking at images of revered human predecessors. There is a long tradition of memorializing animals, but such posthumous fame will not mean anything to a dog.

Martin Kemp is professor of the history of art at the University of Oxford, Oxford OX11PT, UK, and author of The Human Animal in Art and Science. 